\title{
Penile Carcinoma
}

National Cancer Institute

\section{Source}

National Cancer Institute. Penile Carcinoma. NCI Thesaurus. Code C9061.

A carcinoma that arises from the penis. Risk factors include phimosis and human

papillomavirus infection. The majority of penile carcinomas are squamous cell

carcinomas. The most frequent clinical presentation is an irregular mass in the glans of the penis. Treatment includes surgical management and radiation therapy. 